\title{
O mito de Narciso em imagem, palavra e selfie: relações dialógicas entre Ovídio, Caravaggio e Singer
}

\author{
Diogo Souza Cardoso \\ Universidade Presbiteriana Mackenzie (IPM), São Paulo, São Paulo, Brasil \\ discardososter@gmail.com \\ https://orcid.org/0000-0002-9515-9764
}

DOI: http://dx.doi.org/10.21165/el.v47i3.2018

\begin{abstract}
Resumo
Este estudo parte do poema A história de Eco e Narciso, de Ovídio (2003). Desse texto, chega-se a uma reflexão sobre as relações dialógicas possíveis com a pintura Narciso (1599-1600) de Caravaggio e com a charge Take a selfie, de Andy Singer. Constrói-se uma análise discursiva que envolve um processo interdisciplinar entre literatura, pintura e charge, palavra e imagem em constante relação, alcançando o fenômeno do selfie, que possibilita um estudo sobre o autorretrato como no fenômeno do selfie tão presente na era das redes sociais. Procura-se desbravar a imagem do eu, defendendo a auto representação como um outro-para-si. A Análise Dialógica do Discurso é a base epistemológica desse estudo, com destaque para filosofia da linguagem de Bakhtin (2006, 2003, 1997), abordando conceitos como o de enunciado concreto e cronotopia.
\end{abstract}

Palavras-chave: relações dialógicas; autorretrato; Narciso; pintura; selfie.

Le mythe de Narcisse dans l'image, dans les mots et dans le selfie: les relations dialogiques entre Ovídio, Caravaggio et Singer

\section{Résumé}

Ce travail présente une réflexion sur le mythe de Narcisse d'après la version d'Ovide (2003). À partir de cette version du mythe, relations dialogiques sont possibles avec la peinture Narcisse (1599-1600), de Caravaggio, et avec le dessin de presse Take a selfie, de Andy Singer. Il s'agit d'une analyse discursive qui englobe un procès interdisciplinaire entre la littérature, peinture et le dessin de presse, le verbal et le visuel dans une relation intense en parvenant au phénomène du selfie qui possibilite une étude sur l'autoportrait comme le phénomène du selfie dans l'ère des médias sociaux. L'objectif, ici, est défricher l'image du "je" en défendant l'auto-représentation qui révèle le soi-même comme un autre. La base épistémologique pour cette étude est l'analyse dialogique du discours et l'emphase porte sur la philosophie du langage, de Bakhtin (2006, 2003, 1997) en traitant des concepts comme l' énoncé concret et le chronotope.

Mots-clés: relations dialogiques; autoportrait; Narcisse; peinture; selfie.

\section{Considerações iniciais}

Em uma interação entre literatura e artes visuais, neste artigo, buscam-se interconexões que são possíveis destacar por meio das relações entre o verbal e o visual. A proposta dissertativa trata de uma análise do verbo-visual, palavra e imagem em constante relação, corpo discursivo no qual a linguagem verbal e a visual não podem ser separadas, como assim elucida Brait (2013, p. 44): 
[...] dimensão verbo-visual de um enunciado, de um texto, ou seja, dimensão em que tanto a linguagem verbal como a visual desempenham papel constitutivo na produção de sentidos, de efeitos de sentido, não podendo ser separadas, sob pena de amputarmos uma parte do plano de expressão e, consequentemente, a compreensão das formas de produção de sentido desse enunciado, uma vez que ele se dá a ver/ler, simultaneamente [...].

Porém, o referente estudo contribui também para análises que tratam da verbovisualidade, já que mantém um diálogo constante entre palavra e imagem, atentando-se às produções de sentido que se dão na relação entre o Narciso verbal e os pictóricos. A filosofia bakhtiniana apresenta uma teoria da linguagem não apenas verbal, e sim geral, como alerta Brait (2013, p. 44):

[...] os estudos de Bakhtin e do Círculo constituem contribuições para uma teoria da linguagem em geral e não somente para uma teoria da linguagem verbal, quer oral ou escrita [...]. No que se refere às sugestões sobre o visual, de forma especial, mas não exclusiva, poderíamos citar $\mathrm{O}$ autor e a personagem na atividade estética [...].

No âmbito da verbo-visualidade, objetiva-se, aqui, com base na Análise Dialógica do Discurso (ADD), analisar os efeitos de sentido possíveis que advêm dos heróis Narcisos, seguindo principalmente os postulados de Bakhtin $(2006,2003,1997)$.

\section{Análise dialógica dos Narcisos}

No mito de Ovídio, Narciso não identifica à primeira vista que a imagem refletida nas águas é seu reflexo, conforme é possível constatar no trecho abaixo em que ele se dirige ao seu amado (o reflexo) como "seja lá quem for":

[...] Ele está ansioso, Para que eu o abrace. Quando meus lábios se aproximam Para beijar a lagoa, os dele se aproximam dos meus. Você diria que estou prestes a tocá-lo - um quase nada Nos separa. Venha até mim, seja você quem for! Por que me provoca assim? Aonde você vai Quando tento alcançá-lo? [...]. (OVÍDIO, 2003, p. 64).

O seu reflexo é exposto como um ser autônomo, que tem vida própria, Narciso se dirige a ele por meio do pronome você: "Aonde você vai / Quando tento alcançá-lo?" assim como se dirige ao interlocutor leitor: "Você diria que estou prestes a tocá-lo". E, mesmo após descobrir que a imagem nas águas é o seu reflexo, este não perde a autonomia, como é possível constatar no seguinte enunciado: "Sei/ A verdade, finalmente. Você é eu! Sinto isso, / Reconheço minha imagem agora" (OVÍDIO, 2003, p. 64). Por mais que Narciso se aproprie da imagem por meio do pronome possessivo minha, ainda há o distanciamento, ou certa autonomia do reflexo, perceptível por meio da heterogeneidade enunciada, ou seja, pelas marcas linguísticas que assinalam a presença do outro. Neste caso, ela se mostra por meio do uso de é em vez de sou. Logo, é o você que é, é o você que existe, é o você o foco, embora este esteja tão ligado ao eu.

Abaixo, a pintura Narciso, de Caravaggio: 


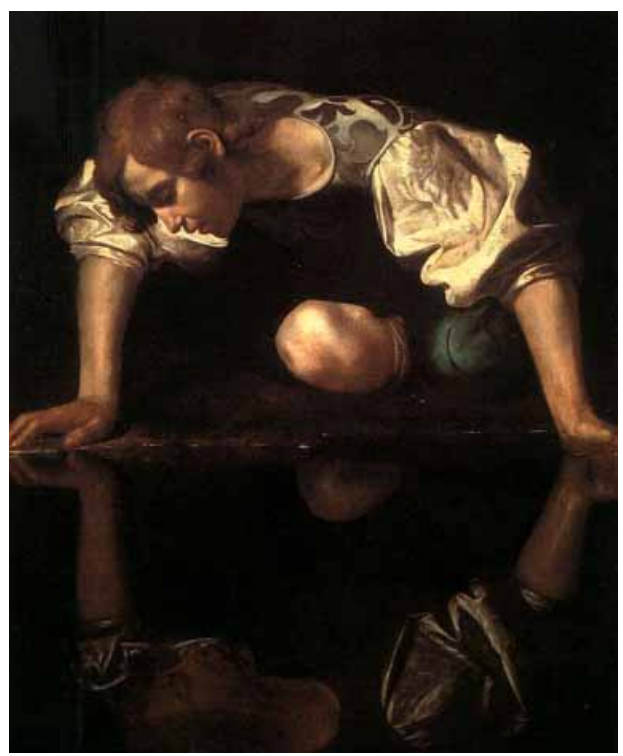

Figura 1. Caravaggio. Narciso, 1599-1600, óleo sobre tela. Galeria Nacional de Arte Antiga, Roma. Disponível

em:

$<$ http://www.auladearte.com.br/historia_da_arte/caravaggio.htm\#axzz38hzdAVBS $>$. Acesso em: 27 jul. 2014.

Nessa arte pictórica, tal distanciamento é marcado por elementos propícios ao gênero a qual pertence. Aqui, no caso, ele é manifestado, por exemplo, pela representação de uma fina camada de água que separa Narciso de sua imagem, fato posto no contato das mãos com a água:
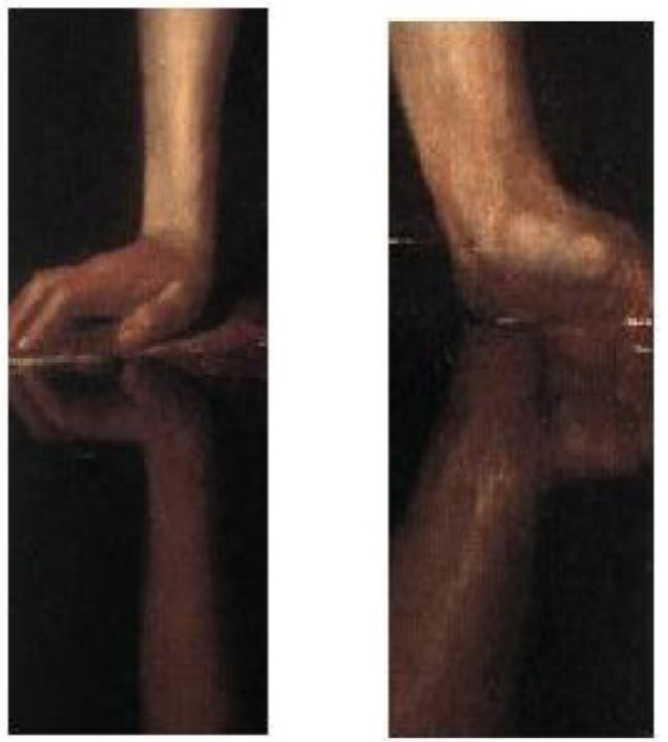

Figura 2. Recorte da obra: Narciso, de Caravaggio. In: AVEIRO, Valéria Rocha. O mito de Narciso, um conto, uma pintura: o enovelar-se. Disponível em: <www.abralic.org.br/enc2007/anais/47/426.pdf >. Acesso em: 21 mar. 2009.

$\mathrm{Na}$ imagem acima, enquanto a sua mão esquerda transpõe a água, a direita permanece em parte na terra, logo, esta não está tão entregue como a outra. Assim, podese dizer que Narciso, em parte, ainda reluta em entregar-se totalmente, em aderir a uma fusão que pudesse anular o outro. Sobre esse fato, podem vir à tona os dizeres de Bakhtin a respeito da percepção real que demarca a fronteira com o mundo exterior único: 
Assim acontece com a percepção real; em um mundo exterior único que eu posso ver, escutar e apalpar, eu não encontro minha expressividade externa enquanto objeto único igualmente externo, ao lado de outros objetos, eu me encontro numa espécie de fronteira do mundo que vejo, não sou conatural com ele em termos plástico-picturais (BAKHTIN, 2003, p. 26).

Narciso mantém, logo, a distância necessária para a existência do seu reflexo como o outro, ou seja, não transpõe a fronteira do mundo que ele vê. Ele não se torna conatural ao seu reflexo, que se encontra em um mundo exterior único. O próprio mito nos versos de Ovídio remete a uma fina camada de água, não que ela seja a responsável pela separação dos Narcisos, mas ela pode ser vista como uma demarcação.

A respeito da manifestação e da complexidade desse dualismo existente entre Narciso e seu reflexo, podem vir à tona questões referentes ao extraverbal, que é tratado na filosofia de Bakhtin. Afirma o filósofo:

[...] as unidades reais da cadeia verbal são as enunciações. Mas, justamente, para estudar as formas dessas unidades, convém não separá-las do curso histórico das enunciações. Enquanto um todo, a enunciação só se realiza no curso da comunicação verbal, pois o todo é determinado pelos seus limites, que se configuram pelos pontos de contato de uma determinada enunciação com o meio extraverbal e verbal (isto é, as outras enunciações) (BAKHTIN, 2006, p. 127).

Levando-se em consideração o extraverbal, vem à tona o cronotopo, ou seja, o tempo e o espaço que fazem parte da constituição da obra. Assim, é de extrema importância o momento histórico do Narciso de Caravaggio, século XVII, que ajuda a compor o dualismo presente na obra, representado pelos dois Narcisos, fazendo referências ao conflito do homem barroco, que é dividido entre o profano e o divino, matéria e espírito. No caso de Narciso, vê-se a clara oposição entre o mundo idealizado, que é o seu reflexo que o remete a uma transcendência, e o espaço em que ele realmente se encontra. Essa ação efetiva do extraverbal, fator que evoca a enunciação, que bombeia significação ao enunciado, possibilita que se possa dizer que o Narciso de Caravaggio é um enunciado concreto.

A relação de Narciso com o seu reflexo, que aponta para uma certa autonomia deste, possibilita que venha à tona, por meio de relações dialógicas, a filosofia de Sartre (2008) sobre coisa e imagem. O filósofo, em sua teoria, utiliza como exemplo o ato de ver uma folha branca sobre uma escrivaninha. Enquanto ele olha essa folha branca, colhe informações sobre ela como forma, cor e posição. E tais características da folha não dependem de seu capricho, há apenas constatação, Sartre (2008, p. 7) diz: "não dependem de nenhuma espontaneidade, nem da minha, nem da de outra consciência". Para o filósofo, as coisas conseguem escapar do domínio da consciência, graças ao fato de serem inertes, pois a inércia é a responsável por conservar a autonomia da coisa. Sartre define "coisa" como uma forma inerte, que está aquém de todas as espontaneidades conscientes e que deve ser observada e apreendida aos poucos. Depois de definir o que é coisa, ele trata da imagem. Ele parte do ato de retirar a folha branca de seu campo de visão, simplesmente, ao virar-se, dirigindo o olhar para uma parede. Fora de seu campo de visão a folha aparece, novamente, para ele com as mesmas características de outrora: cor, posição e forma. Entretanto, ela existe em um plano diferente, ela existe como imagem. A folha da imagem e a folha real mantêm uma mesma identidade de essência e não de 
existência. Se mantivessem uma mesma relação de existência seria impossível distinguir uma folha da outra.

Narciso vê o seu reflexo como se visse uma folha branca, uma coisa. Essa coisa possui uma forte carga significativa. Nela, ele projeta a imagem que ele tem de si mesmo, o reflexo passa a funcionar como um ídolo, assim, trata-se de um invólucro com as características do herói, segundo Sartre (2008, p. 10): "Esses invólucros têm todas as qualidades do objeto, do conteúdo, da forma, etc. São mesmo, exatamente, objetos. Uma vez emitidas, elas existem em si tanto quanto o objeto emissor".

O reflexo é o ídolo, o invólucro que tem todas as qualidades do objeto (Narciso). O ídolo, segundo a primeira acepção da palavra no dicionário Houaiss (2004, p. 397), é adorado "como se fosse a própria divindade". E a divindade de Narciso é ele próprio. Ele vê em seu ídolo a sua imagem coisificada. E aí está feito o seu erro, pois a imagem não existe como coisa. Sartre denomina de "metafísica ingênua da imagem" a confusão entre identidade de essência e identidade de existência: "E ele acaba de constituir em vez de uma única folha de papel em dois planos de existência, duas rigorosamente semelhantes que existem no mesmo plano" (SARTRE, 2008, p. 10). Porém, deve-se alertar que a experiência de Narciso, referente à coisificação de seu reflexo, não o duplica, pois o seu reflexo não funciona como o eu-para-si, e sim, como o outro-para-si. O reflexo não é a imagem externa de Narciso incorporada a um conjunto externo vivo, caso assim fosse, tal imagem iria carecer de autonomia. Assim explica Bakhtin (2003, p. 29-30) sobre o processo de contemplar a própria imagem externa:

De fato, quando contemplo minha imagem externa - como viva e incorporada ao conjunto externo vivo - pelo prisma da alma avaliadora do outro possível, essa alma do outro, desprovida de autonomia, alma-de-escravo insere um elemento falso e inteiramente estranho ao acontecimento-existência ético: não é uma geração produtiva e enriquecedora, porque [essa] geração carece de valor autônomo, é um produto falso, fictício, que turva a pureza óptica da existência; aqui parece ocorrer uma fraude óptica, cria-se uma alma sem espaço, um participante sem nome nem papel, algo absolutamente extra-histórico.

O reflexo de Narciso não carece de valor autônomo, pois ele fala de um lugar único no qual ele assume um papel de interlocutor direto. Se ele carecesse de valor autônomo, se ele fosse uma mera imagem de Narciso, este o destruiria com sua autoconsciência, segundo Bakhtin: "Minha autoconsciência destrói a capacidade de persuasão plástica de minha imagem" (BAKHTIN, 2003, p. 37), e, como aqui já foi apontado, o reflexo não perde autonomia nem mesmo após Narciso se reconhecer nas águas.

Essa coisificação, em Narciso, exemplifica a sempre presença do outro, a pressuposição responsiva que emana de qualquer enunciado. De fato, se Narciso não coisificasse seu reflexo, este não seria inerte e, por fim, não assumiria o papel de seu interlocutor. O interlocutor na filosofia de Bakhtin (1997, p. 321-322) pode ter diversas formas, assim afirma o filósofo:

O enunciado tem autor (e, correlativamente, uma expressão, do que já falamos) e destinatário. Este destinatário pode ser o parceiro e interlocutor direto do diálogo na vida cotidiana, pode ser o conjunto diferenciado de especialistas em alguma área especializada 
da comunicação cultural, pode ser o auditório diferenciado dos contemporâneos, dos partidários, dos adversários e inimigos [...] pode até ser, de modo absolutamente indeterminado, o outro não concretizado (é o caso de todas as espécies de enunciados monológicos de tipo emocional). Essas formas e concepções do destinatário se determinam pela área da atividade humana e da vida cotidiana a que se reporta um dado enunciado.

Narciso, assim, encontrou, em seu reflexo, o outro a quem se dirige, ainda que este não tenha um corpo de carne e osso. Um outro cuja constituição tem como base criadora a sua imagem coisificada.

Narciso, ao ver o seu reflexo, vê, ao mesmo tempo, o discurso do outro. A ação de se olhar no espelho não é uma ação discursiva solitária, aliás, não há discurso isolado, isso é impossível do ponto de vista dialógico, frente ao espelho, compenetra-se um outro possível e indefinido, como afirma Bakhtin (2003, p. 30):

[...] nossa situação diante do espelho é meio falsa: como não dispomos de um enfoque de nós mesmos de fora, também nesse caso nos compenetramos de um outro possível e indefinido, com cuja ajuda tentamos encontrar uma posição axiológica em relação a nós mesmos; também aqui tentamos verificar e enformar a nós mesmos a partir do outro; daí a expressão original e antinatural de nosso rosto que vemos no espelho [e] que não temos na vida.

Pode-se refletir sobre essa imagem especular no fenômeno do selfie no qual o culto da autoimagem mantém relações dialógicas com o mito de Narciso. Cada selfie é um autorretrato, que permite que o eu construa uma imagem sua que exista virtualmente. O selfie ao ser postado nas redes sociais abre diversos olhares sobre ele, que vão julgá-lo, por exemplo, em cada curtida, comentário etc.

A seguir, uma charge de Andy Singer (2014) que aborda o selfie, o título é Narcissus Takes a Selfie.
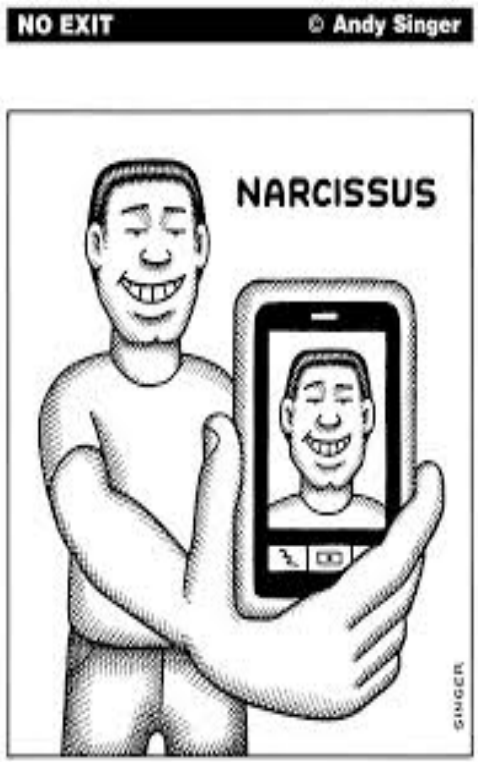

Figura 3. SINGER, Andy. Narcissus take a selfie. 2014. Disponível em: $<$ www.cagle.com/andy-singer/2014/03/narcissus-takes-a-selfie>. Acesso em: 20 set. 2014. 
Na charge, no engendramento do autor criador, percebe-se que se trata da representação de um selfie que é tirado frente ao espelho, pois o celular aparece no enquadramento, sendo posicionado pelo personagem intitulado Narcissus, em um ângulo propício para a captação de sua face. O nome do personagem proporciona ao espectador fazer relações com o mito de Narciso em que a presença do reflexo, ou seja, da autoimagem, é uma forte característica para identificá-lo.

Em representações pictóricas desse mito é comum ter a presença da imagem real de Narciso e a de seu reflexo. Mas na charge de Singer, há apenas o reflexo, o resultado do selfie é uma autoimagem filtrada pela câmera e pelo espelho, chegando ao espectador a imagem especular e não a de Narciso. Espelho que pode ser concretizado na própria superfície pictórica, que é denominada por Kandinsky como P.O (plano original). O plano original

"é a superfície material destinada a suportar o conteúdo da obra [...]. O P.O. esquemático é limitado por duas linhas horizontais e duas verticais, sendo assim definido como um ser autônomo no domínio de seu entorno" (KANDINSKY, 1997, p. 105). Nessa charge, esse plano não é apenas um enquadramento do desenho, não é autônomo no sentido de estar isolado, e sim, ele se integra ao conteúdo, ascende também para o papel de espelho, graças à realidade discursiva na qual ele se encontra.

O nome Narcissus, por se encontrar suspenso ao lado da cabeça do personagem e ao mesmo tempo na parte superior do celular, pode se referir ali às duas imagens, tanto à imagem do celular quanto à do personagem que segura o aparelho. É possível que o nome Narcissus se refira também à própria ação do reflexo, a essa busca e ao próprio espelho em si, pois o nome se encontra fixado na superfície especular. Trata-se da velha problematização de tomar a imagem como a coisa de fato. Questão discutida, por exemplo, na obra La trahison des images, de René Magritte, na qual a frase, presente como parte pictórica da imagem, alerta que o desenho do cachimbo não é o mesmo, não é a coisa:

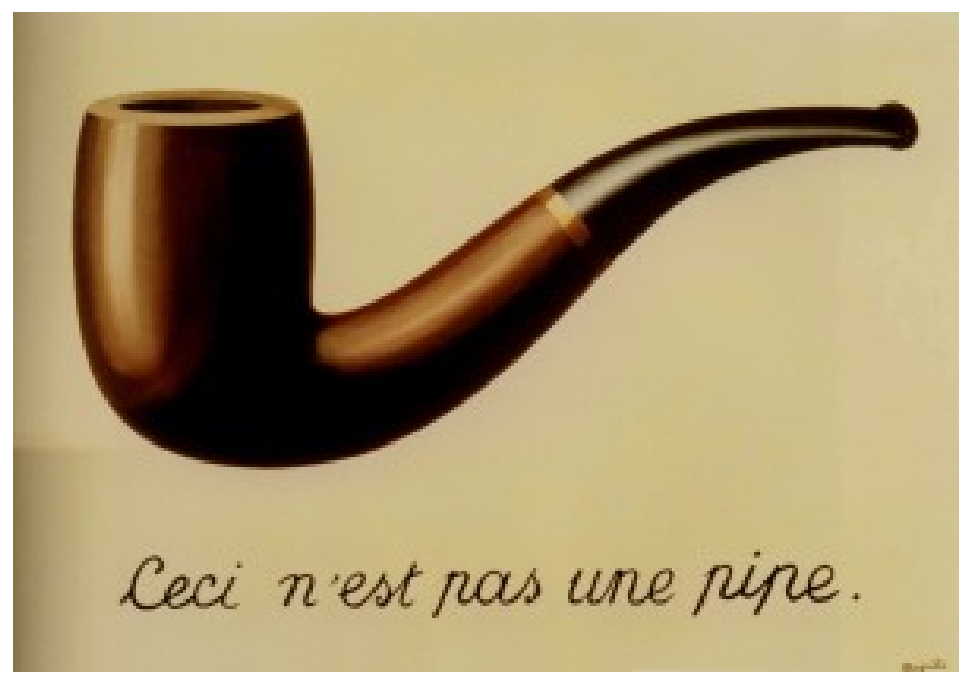

Figura 4. MAGRITE, René. Ceci n'est pas une pipe, 1929. Disponível em: <http://g1.globo.com/pop-arte/blog/yvonne-maggie/post/isto-nao-e-um-cachimbo.html>.

No Narcissus de Singer não é claro definir quem de fato é Narciso, o certo é a presença do reflexo, não há a imagem real de Narciso, o reflexo ganha lugar absoluto. É 
construído um discurso no qual o selfie, assim, é o lugar reservado para os reflexos, para a manifestação e protagonismo destes, para uma autoimagem que passa pelo grifo do outro, desde a sua concepção na qual perpassam vozes na sua criação, estabelecendo-se como enunciado, chegando por fim à sua recepção nas redes sociais. O clamor pelo olhar do outro se mostra claramente quando se percebe a imagem presente no celular dirigida para o espectador, dirigida e bem enquadrada, em um plano principal no qual se pega $o$ busto, semelhante às famosas fotos $3 \times 4$ como a de um documento de identidade, semelhante a um retrato tradicional.

Na charge de Singer, pode-se refletir sobre identidade da imagem do selfie, ao ter relações dialógicas com o mito de Narciso; vê-se o selfie como um fenômeno que carece de um plano real do ser, já que há apenas o reflexo. Reflete-se sobre o que de fato a imagem do selfie representa e o papel do outro na concepção e veiculação da imagem.

\section{Considerações finais}

Neste artigo, à luz da Análise Dialógica do Discurso (ADD), foi possível trabalhar com a verbo-visualidade, aproximando esferas da arte por meio de Narcisos verbais e pictóricos, ampliando, assim, o olhar sobre o mito. Tornou-se possível analisar a autonomia dos reflexos, que os caracterizou como o outro no discurso, reflexos dotados de voz, seres de resposta. Um exemplo disso é o reflexo como imagem coisificada, que se estabelece como interlocutor a partir do diálogo que se constitui com Narciso.

A análise verbal e visual dos Narcisos, do corpus deste estudo, ainda possui um longo caminho a ser percorrido. É possível aprofundar mais, por exemplo, as relações dialógicas de Narciso com o reflexo, com a ninfa Eco, com o Narrador e até mesmo com o interlocutor leitor. Este pesquisador está ciente de que há ainda muito a ser feito e, o mais importante, que nunca haverá um estudo acabado, que seja livre de inferências. Assim, ficam aqui propostas para análises futuras.

\section{REFERÊNCIAS}

AVEIRO, V. R. O mito de Narciso, um conto, uma pintura: o enovelar-se. 2007. Disponível em: < $\underline{w w w . a b r a l i c . o r g . b r / e n c 2007 / a n a i s / 47 / 426 . p d f ~}>$. Acesso em: 21 mar. 2009.

BAKHTIN, M. A forma espacial da personagem. In: BAKHTIN. M. Estética da criação verbal. Tradução de Paulo Bezerra. São Paulo: Martins Fontes, 2003. p. 21-84. . Marxismo e filosofia da linguagem. 12. ed. São Paulo: Hucitec, 2006. 1997. . Problemas da poética de Dostoiévski. 2. ed. São Paulo: Forense Universitária,

BRAIT, B. Olhar e ler: verbo-visualidade em perspectiva dialógica. Bakhtiniana, São Paulo, 8 (2), p. 43-66, jul./dez. 2013. Disponível em: $<$ http://www.scielo.br/pdf/bak/v8n2/04.pdf $>$. Acesso em: 07 jun. 2014.

HOUAISS, A.; VILLAR, M. de S. Minidicionário Houaiss da língua portuguesa. 2. ed. Rio de Janeiro: Objetiva, 2004. 
KANDINSKY, W. Ponto e linha sobre plano. Tradução de Eduardo Brandão. São Paulo: Martins Fontes, 1997.

OVÍDIO. Metamorfoses. Tradução de Vera Lucia Leitão Magyar. São Paulo: Madras, 2003.

SARTRE, J.-P. A imaginação. Tradução de Paulo Neves. Porto Alegre: LPM, 2008.

CARAVAGGIO. Narciso, 1599-1600, óleo sobre tela. Galeria Nacional de Arte Antiga, Roma.

Disponível em:

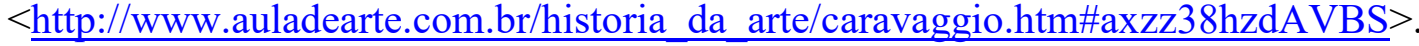
Acesso em: 27 jul. 2014.

MAGRITE, R. Ceci n'est pas une pipe, 1929. Disponível em: $<\underline{\text { http://g1.globo.com/pop- }}$ arte/blog/yvonne-maggie/post/isto-nao-e-um-cachimbo.html $>$. Acesso em: 27 jul. 2014.

SINGER, A. Narcissus take a selfie. 2014. Disponível em: <www.cagle.com/andysinger/2014/03/narcissus-takes-a-selfie $>$. Acesso em: 20 set. 2014.

Recebido em: 25/09/2017

Aprovado em: 21/08/2018 